\title{
PACKAGE OPENING: AN EVALUATION OF OPENING TOOLS FOR THE ELDERLY POPULATION
}

\author{
Chaitanya Saha ${ }^{1}$, Randa L. Shehab ${ }^{2}$ \\ ${ }^{1}$ University of Wisconson, Madison, Wisconson, USA \\ ${ }^{2}$ University of Oklahoma, Norman, Oklahoma, USA
}

Opening packages is becoming more difficult with manufacturers making packaging harder to tamper with. Consumers must apply greater force or use tools to aid them in opening. With aging, the amount of force that can be applied reduces considerably which makes it important to view the packaging problem from the perspective of the older population. The objective of the current study was to determine the effectiveness of opening tools in opening different kinds of packages. The study revealed that the tools are mostly ineffective and do not improve performance beyond the use of the hands alone. In addition, the more complex the tool, the less effective the tool was as an aid to open packaging.

\section{INTRODUCTION}

Packaging has always been an important concern for manufacturers as well as for consumers. Although the concept of packaging originated in the early 1800 's, it was not until the mid- $20^{\text {th }}$ century that it was viewed from the perspective of the consumer (CMA, 2003). Package opening is an essential part of everyone's daily activities. The majority of people come across packaging that they must open.

The population of the world is aging at a rapid pace. According to the United Nations (UN, 1999), one out of every 10 persons is above the age of 60 years. This number will climb to 1 out of every 5 by the year 2050, and 1 out of every 3 by 2150 .

With the increasing elderly population, particularly those that live independently, more and more elderly consumers are finding it necessary to open packaging. However, with aging the amount of force one can produce to open packages is reduced, particularly for people aged 65 and older (Kallman, 1990). A large number of tools have been developed to facilitate package opening. This study evaluated the ability of some of the commercially available opening tools to open four different kinds of packaging.

\section{PROBLEM DEFINITION}

One of the primary conflicts in product packaging design is making packaging easy for consumers to open as well as hard for people to tamper with. Attention on the latter issue has become so prominent that it has generally been left to the consumer to figure out the easiest way to open a package. Many previous studies in the area of packaging usability for the elderly population have described acceptable levels of torque and force to open different kinds of lids (Berns, 1981; Voorbij, 2002) using simulated bottle opening.

Manufacturers have introduced tools designed to either open a specific kind of package or to aid in opening more than one type of package. The only previous study to focus on opening tools used subjective evaluations of the ease of opening packages using tools (DTI, 1999).

The goal of the current study was to compare the ease of opening packages with and without the use of tools. Objective measures of time to open and number of attempts to open were measured along with the subjective measure of rated difficulty. It was hoped to determine if opening tools minimize the demands of packaging opening without creating additional demands on the user.

\section{PROCEDURE}

Participants:

Participants in this study were sampled from two age groups. The younger participants were college students between 20 and 40 years of age (mean $=22.3$ years). The older participants were 65 years and older and were recruited from independent living centers in the local community. The study included 47 participants, 20 males ( 11 older) and 27 females (16 older). Since the experimental task involved repeated opening of bottles, a pre-test questionnaire was used to screen for participants who might find the opening task uncomfortable. The participants were asked to report their 
discomfort level for a variety of upper extremity diseases using a scale of 1 to 4 (1 - very minor/infrequent discomfort, 4 - acute/continual discomfort). Any participant who reported more than moderate or occasional discomfort was excluded from the study.

\section{Variables:}

There were three independent variables, age, type of package, and method of opening. The two age groups considered in this study were 20 - 40 years old and 65 years and older. Four types of packaging were evaluated: continuous thread, push and turn, tamper evident, and vacuum package. There were nine methods of opening tested in the present study, eight tools and the use of hands. These tools were identified from a search of retail products designed to open different types of packages. Only tools using different opening principles for different packaging types were selected. However, due to the nature of the tool designs, all methods of opening were not usable on all packages. Figure 1 shows the four types of packages and the particular opening tools that were usable with each package type.

Three different measures were used to determine how effective opening tools are for an older population opening bottles and jars. The time to open the package was calculated by subtracting the time when the participant first grasped a tool to open a bottle from the time when the participant finally released the lid of the bottle, and was inclusive of all attempts made by a participant on a given trial. The number of attempts required to open the packages and the rated difficulty were also measured. A single attempt was defined from the point the participant set the tool on the bottle to open it to the point the participant took the tool off. The difficulty was rated on a scale of 1 to 5 (1 - easy, 5 - unable to open).

Previous studies conducted to measure grip strength controlled the position of the upper extremity. Terrell (1976), Mathiowetz (1985), and Pryce (1980) asked participants to keep their elbow in a $90^{\circ}$ flexed position. A similar approach was used in the present study. Moreover all of the participants were asked to keep their elbow as close to their body as

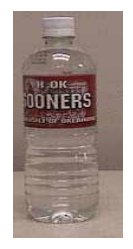

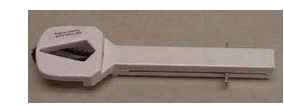

Adjustable CapGrippa ${ }^{\circledR}$

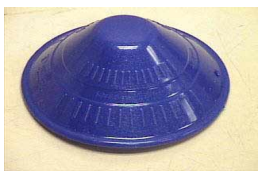

Dycem $^{\mathrm{TM}}$

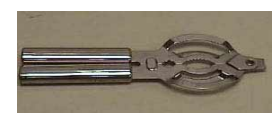

Pedrini

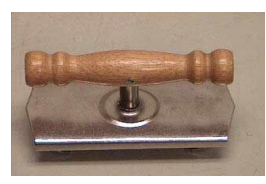

Twist-off

\section{Continuous Thread}

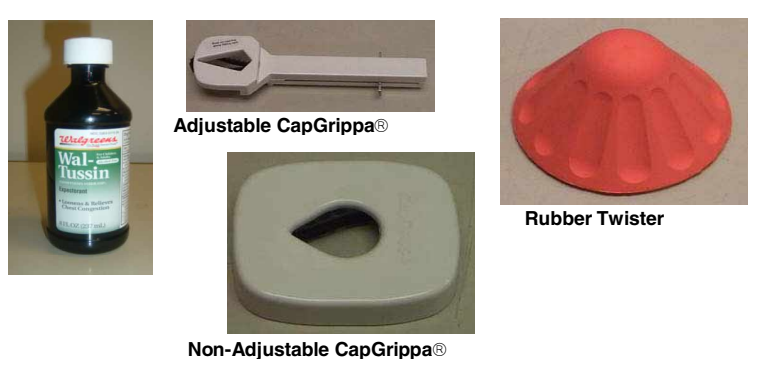

\section{Push and Turn}

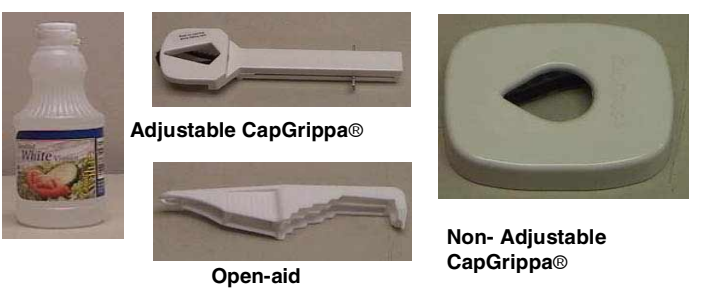

Tamper Evident
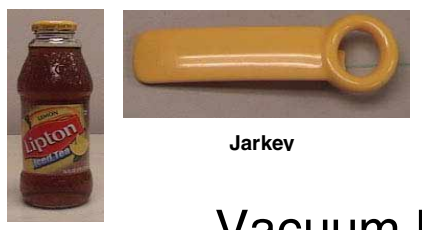

Jarkev

\section{Vacuum Package}

\section{Figure 1: Methods of opening tested with} each package.

possible to minimize the use of shoulders during opening. All of the participants were given the same set of instructions and were asked to use their right hand to open the bottles.

\section{Equipment:}

The motion of both hands was recorded using two video cameras. The first camera was placed orthogonally above the center of the 
bottle. The height of the camera was adjusted such that it was able to capture complete movement of both hands. The second camera was placed perpendicular to the participant's right hand. Data were later transferred from the video camera to a computer for measurement of time to open and number of attempts.

Measurements were made only for the successful trials that resulted in opening of the package.

\section{Methodology:}

Participants were asked to open each of the 16 package-tool combinations once. The treatment order was randomized. Manufacturer instructions were provided as available (for the adjustable capgrippa, the non-adjustable capgrippa, and the open-aid cap remover). Participants were allowed to take a break at any time during the experiment if they felt tired or fatigued.

Once participants completed all 16 trials, they were asked to complete a post-test questionnaire to evaluate both the packages and the tools. Participants rated both the ease of use and their preference for the different packages and tools. They also provided comments about difficulties encountered during the experimental trials. To minimize hand strain and discomfort for the older participants, the questionnaires were administered verbally and responses recorded by the experimenter. The study took about 40 minutes per participant.

\section{Experimental Models:}

Because of the inability to use all methods of opening on all package types, several separate analyses were required to fully examine the data. The models are shown with the data and analyses in Table 1.

To simultaneously compare all package types collapsed across method of opening, a repeated measures model was used with age as a between-subjects effect and package type as a within-subjects effect (A). A second analysis was performed using the same model but restricting the method of opening to the use of the hands (B).

The second experimental model was used to examine method of opening. Again, a repeated measures design was used with age as the between-subjects effect and method of opening as the within-subjects effect. However, five variants of this model were used for analysis. The first analysis collapsed the data across package type and simultaneously evaluated all nine methods of opening $(\mathrm{C})$. Each of the other four analyses used data specific to one package type (D-G).

In order to examine the combined effects of package type and method of opening, two additional analyses used a repeated measures model with age as a between-subjects effect and package type and method of opening as within-subjects effects. The data set was subdivided into subsets containing only crossed factors. The first of these analyses restricted package type to continuous thread, push and turn, and tamper evident and restricted method of opening to adjustable capgrippa and no tool $(\mathrm{Ha} \& \mathrm{~b})$. The second of these analyses restricted package type to push and turn and tamper evident and restricted method of opening to adjustable capgrippa, non-adjustable capgrippa, and use of the hands (I).

\section{RESULTS}

Table 1 summarizes the nine analyses and provides the mean data for the different levels of the main effects and the p-values for the tests on age in each analysis. The analyses showed that the older participants were slower opening bottles in all cases except for a few cases when opening the tamper evident bottle and using the open-aid remover (indicated with shading in Table 1). The older participants also required more attempts than the younger participants on most trials. The exceptions were again found on the trials involving the tamper evident package and the open aid, as well as one trial using the non-adjustable capgrippa.

Average times to open the different package types across all tools indicated a slight advantage for the vacuum package. However, this advantage essentially disappeared when only the hands were used. In terms of the method of opening, the only method that even approached the times obtained without a tool was the rubber twister. The two varieties of the capgrippa, the rubber twister, and the open-aid, all performed very poorly, regardless of package type (see the bold data points in Table 1). These 
same results were confirmed even when the data set was parsed down to run factorial models.

Examination of the number of attempts to open confirmed the noted problems with the adjustable capgrippa. This tool was particularly problematic for the older participants when combined with the tamper evident package. The jarkey tool required both ages of participants to use more attempts to open packages. However, even though more attempts were required, the average opening time was only somewhat elevated, and certainly not one of the slowest tools.

The older participants reported the same level of difficulty as the younger participants in opening the push and turn and the continuous thread packages. However, the older participants reported less difficulty in opening the tamper evident and vacuum packages. The adjustable capgrippa, used for continuous thread, push and turn, and tamper evident packages, posed serious problems for participants in both age groups. The non-adjustable capgrippa was also problematic. The jarkey opener, used to open vacuum packages, was also difficult for all participants.

\section{DISCUSSION}

Participants in this study were asked to use the opening tools without provision for practice. Since many of the tools did not come with instructions, we did not want to bias participants towards a particular method of use when little manufacturer guidance was given on this issue. It was decided to observe how a participant initially interacts with a tool as if just purchased off-the-shelf. This quality of this first interaction is critical and determines the future use of the tool.

This study indicates that the use of packaging opening tools is not effective. Overall, the use of hands was the least time consuming method of opening and required the fewest number of attempts. Multi-purpose tools like the adjustable capgrippa and the nonadjustable capgrippa were found to be problematic with regard to all measures of performance. It appeared that these tools were not intuitive and placed a cognitive burden on the individual in addition to the physical burden. The recommendations from this study include the use of the hands alone to open all of the examined package types. However, the rubber twister was effective for opening the push and turn package. While this marked preference for use of the hands could be due to familiarity with that method, it is felt that the tools currently onthe-market are not simple enough for use by any age group. Certainly, the more complex tools are completely ineffective at opening packages.

\section{ACKNOWLEDGEMENTS}

The authors would like to thank Rambling Oaks Assisted Living Center, Arbor House Assisted Living Center, and The Senior Citizens Center of Norman for permitting us to conduct a part of our study at their respective centers.

\section{REFERENCES}

Berns, T. (1981). The Handling of Consumer Packaging. Applied Ergonomics, 12(3), 153-161.

Closure Manufacturers Association (CMA). (2003). History of Closures. Retrieved August 1, 2003 from http://www.cmadc.org/history_closures.tpl.

Department of Trade and Industry (DTI). (1999), Use and misuse of packaging opening tools (URN 99/619). London: DTI.

Kallman, D.A., Plato, C.C., and Tobin, J.D. (1990). The role of muscle loss on the age-related decline of grip strength: Cross-sectional and longitudinal perspectives. Journal of Gerontology, 45(3), M82-88.

Mathiowetz, V., Kashman, N., Volland, G., Weber, K., Dowe, M., and Rogers, S. (1985). Grip and pinch strength: normative data for adults. Archives of PhysicalMedicine and Rehabilitation, 66(2), 69-74.

Pryce, J.C. (1980). The wrist position between neutral and ulnar deviation that facilitates the maximum power grip strength. Journal of Biomechanics, 13, 303-311.

Terrell, R. and Purswell, J.L. (1976). The influence of forearm and wrist orientation on static grip strength as a design criterion for hand tools. In Proceedings of the Human Factors Society-20 $0^{\text {th }}$ Annual Meeting (pp.28-32). Santa Monica, CA: Human Factors.

United Nations (UN). (1999). Population Aging. Retrieved May 28, 2004 fromhttp://www.un.org/esa/population/publicatio ns/aging99/a99note.htm.

Voorbij, A.I.M., and Steenbekkers, L.P.A. (2002). The twisting force of aged consumers when opening a jar. Applied Ergonomics, 33, 105-109. 
Table 1. Summary of Statistical Analyses.

\begin{tabular}{|c|c|c|c|c|c|c|c|}
\hline \multirow{2}{*}{ Main Effect } & \multirow{2}{*}{ Levels } & \multicolumn{2}{|c|}{ Ave. Time (in sec) } & \multirow[b]{2}{*}{ p-value } & \multicolumn{2}{|c|}{ Ave. \# Attempts } & \multirow[b]{2}{*}{ p-value } \\
\hline & & \begin{tabular}{l|l} 
Old & \\
\end{tabular} & Young & & \begin{tabular}{l|l} 
Old \\
\end{tabular} & Young & \\
\hline \multicolumn{8}{|c|}{ MAIN EFFECT MODELS } \\
\hline \multirow{4}{*}{$\begin{array}{l}\text { A. PACKAGE TYPE - } \\
\text { methods }\end{array}$} & Continuous Thread & 31.6 & 23.3 & \multirow{4}{*}{0.001} & 1.4 & 1.1 & \multirow{4}{*}{$>0.05$} \\
\hline & Push \& Turn & 31.1 & 22.5 & & 1.8 & 1.7 & \\
\hline & Tamper Evident & 33.3 & 42.6 & & 2.1 & 2.2 & \\
\hline & Vacuum Package & 20.3 & 18.1 & & 2.0 & 1.8 & \\
\hline \multirow{4}{*}{$\begin{array}{l}\text { B. PACKAGE TYPE - } \\
\text { tool }\end{array}$} & Continuous Thread & 12.8 & 6.6 & \multirow{4}{*}{0.0108} & 1.1 & 1.0 & \multirow{4}{*}{0.0049} \\
\hline & Push \& Turn & 12.1 & 7.3 & & 1.8 & 1.3 & \\
\hline & Tamper Evident & 10.5 & 4.9 & & 1.3 & 1.0 & \\
\hline & Vacuum Package & 11.0 & 3.5 & & 1.0 & 1.0 & \\
\hline \multirow{9}{*}{$\begin{array}{l}\text { C. METHOD OF OPENING - } \\
\text { package types }\end{array}$} & Adjustable CapGrippa & 69.3 & 44.6 & \multirow{9}{*}{$<0.0001$} & 2.3 & 1.7 & \multirow{9}{*}{$>0.05$} \\
\hline & Dycem & 25.8 & 15.4 & & 1.5 & 1.0 & \\
\hline & Jarkey & 36.3 & 35.7 & & 5.6 & 4.9 & \\
\hline & Non-Adjustable CapGrippa & 45.4 & 41.3 & & 2.0 & 2.0 & \\
\hline & No Tool & 11.6 & 5.5 & & 1.3 & 1.1 & \\
\hline & Open-Aid & 41.8 & 65.3 & & 2.9 & 4.1 & \\
\hline & Pedrini & 24.7 & 20.6 & & 1.2 & 1.1 & \\
\hline & Rubber Twister & 15.8 & 11.9 & & 1.1 & 1.2 & \\
\hline & Twist-off & 66.0 & 40.9 & & 1.8 & 1.4 & \\
\hline \multirow{5}{*}{$\begin{array}{l}\text { D. METHOD OF OPENING - } \\
\text { continuous thread }\end{array}$} & Adjustable CapGrippa & 56.1 & 38.3 & \multirow{5}{*}{$<0.0001$} & 1.7 & 1.2 & \multirow{5}{*}{0.0013} \\
\hline & Dycem & 25.8 & 15.4 & & 1.5 & 1.0 & \\
\hline & No Tool & 12.8 & 6.6 & & 1.1 & 1.0 & \\
\hline & Pedrini & 22.5 & 18.6 & & 1.1 & 1.0 & \\
\hline & Twist-off & 66.0 & 40.9 & & 1.8 & 1.4 & \\
\hline \multirow{4}{*}{$\begin{array}{l}\text { E. METHOD OF OPENING - } \\
\text { push \& turn }\end{array}$} & Adjustable CapGrippa & 86.5 & 42.2 & \multirow{4}{*}{0.0006} & 2.7 & 2.0 & \multirow{4}{*}{$<0.0001$} \\
\hline & Non-Adjustable CapGrippa & 36.7 & 31.2 & & 1.8 & 1.9 & \\
\hline & No Tool & 12.1 & 7.3 & & 1.8 & 1.2 & \\
\hline & Rubber Twister & 15.8 & 11.9 & & 1.1 & 1.2 & \\
\hline \multirow{4}{*}{$\begin{array}{l}\text { F. METHOD OF OPENING - } \\
\text { tamper evident }\end{array}$} & Adjustable CapGrippa & 73.6 & 55.1 & & 4.0 & 1.9 & \\
\hline & Non-Adjustable CapGrippa & 62.8 & 55.2 & & 2.4 & 2.0 & 0.0114 \\
\hline & No Tool & 10.5 & 4.6 & $<0.0001$ & 1.3 & 1.0 & 0.0114 \\
\hline & Open-Aid & 41.8 & 65.3 & & 2.9 & 4.1 & \\
\hline & Jarkey & 36.3 & 35.7 & & 5.6 & 4.9 & \\
\hline G. IVIETHUD UF UPEIVIIV - vacuum & No Tool & 11.0 & 3.5 & $>0.05$ & 1.0 & 1.0 & $<0.0001$ \\
\hline & Pedrini & 28.7 & 22.5 & & 1.4 & 1.2 & \\
\hline & INTERACT & N MODELS & & & & & \\
\hline & Continuous Thread & 12.8 & 6.6 & & 1.3 & 1.1 & \\
\hline H(a). PACKAGE IYPE X MIEIHOD - & Push \& Turn & 12.1 & 7.3 & & 1.8 & 1.2 & \\
\hline & Tamper Evident & 10.5 & 4.6 & & 1.3 & 1.0 & 00002 \\
\hline & Continuous Thread & 56.1 & 38.2 & $<0.0001$ & 1.7 & 1.2 & 0.0002 \\
\hline (D). PACNAGC ITC A IVICI HUU - & Push \& Turn & 86.5 & 42.2 & & 2.7 & 2.0 & \\
\hline Adjustable CapGrıppa & Tamper Evident & 73.6 & 55.1 & & 3.2 & 1.9 & \\
\hline I. PACKAGE TYPE X METHOD -Non- & Push \& Turn & 36.7 & 31.2 & 00004 & 1.8 & 1.9 & 0.0136 \\
\hline Adjustable CapGrippa & Tamper Evident & 62.8 & 55.2 & 0.0004 & 2.4 & 21.0 & \\
\hline
\end{tabular}

